\title{
Financial Performance Evaluation of Domestic Real Estate Listed Companies Based on Factor Analysis
}

\author{
Qiuxia Lu ${ }^{a}$, Hui Tian, ${ }^{b, *}$ \\ School of Economics \& Management, Nanjing University of Science \& Technology, Nanjing \\ 210094, China \\ a694748599@qq.com, ${ }^{b} 1502094737 @ q q . c o m$ \\ *corresponding author
}

Keywords: Factor analysis, real estate listed company, financial performance evaluation.

Abstract: Based on factor analysis, this paper empirically analyzes 11 financial performance indicators of 20 listed companies in the domestic real estate industry, and calculates 5 common factors to reflect the financial status of China's real estate industry, which is the business decision of senior executives. The supervision of government departments and investors provide reference, which is conducive to the healthy development of listed companies and even the entire industry.

\section{Introduction}

In recent years, the real estate industry has always been a hot topic for the public. In order to increase the understanding of the domestic real estate industry, it is necessary to evaluate and analyze the financial indicators of industrial enterprises. In view of the high correlation between the indicators selected by the performance evaluation methods such as the DuPont analysis method, the balanced scorecard, and the EVA economic value added method, the information overlap is caused.

The factor analysis method is based on the analysis of the internal correlation coefficient matrix of variables. It integrates multiple variables into several common factors for research ${ }^{[1]}$. Its main purpose is to reduce the dimension and use a comprehensive common factor to describe the relationship between multiple indicators ${ }^{[2]}$. Thus, effectively avoiding mutual interference between different indicators. Therefore, this paper chooses factor analysis as a financial indicator evaluation method.

\section{Selection of evaluation indicators and sample data}

This paper analyzes the listed companies in the 20 real estate industries, and uses the financial performance data of the 20 companies in 2016 as a sample. Using the financial data in the latest annual report, we can get the latest financial situation of the industry in a timely manner, and ensure the scientific and timeliness of the article data. At the same time, the listed company's annual financial statements, Juchao Information, Sina Finance, Oriental Wealth Network and Ruisi database disclosed by Shenzhen Stock Exchange and Shanghai Stock Exchange are the main data sources. 
This paper mainly evaluates these 20 listed companies from the financial point of view, and selects the current ratio, the return on net assets, the net profit margin of total assets, and the growth rate of main operating income from four aspects: growth ability, operation ability, solvency and profitability. The 11 financial indicators of accounts receivable turnover rate, fixed asset turnover rate, total asset turnover rate, quick ratio, return on net assets, net asset growth rate, inventory turnover rate and net profit growth rate are used as evaluation indicators. The selection of these indicators takes into account the large capital demand of the real estate enterprises and the large financial risks, so it can reflect the financial performance of these real estate enterprises more comprehensively ${ }^{[3]}$.

Before starting the factor analysis, the original data should be standardized to avoid the influence of data unit inconsistency. The Z-scoer method is adopted in the data standardization. At the same time, some of the financial performance indicators selected in this paper are moderate indicators, such as current ratio and quick ratio, so they need to be forwarded. Let $\mathrm{X}$ be a moderate index, $\mathrm{Y}$ be the index after forward processing, and $\mathrm{K}$ be the theoretical optimal value of this index. The quick ratio theory has an optimal value of 1 and a flow ratio of 2 . The calculation formula is: $y=\frac{1}{|x-k|}$.

\section{The empirical analysis process}

Using SPSS24.0, factor analysis was used to find common factors from 11 relevant financial indicators, and the factor composite scores of 20 companies were calculated and ranked. First, the KMO and Bartlett tests were performed.

\begin{tabular}{|l|c|c|}
\hline \multicolumn{2}{|c|}{ KMO sampling suitability } & 0.520 \\
\hline \multirow{3}{*}{ Bartlett sphericity test } & $\lambda^{2}$ & 102.239 \\
\cline { 2 - 3 } & Degree of freedom & 55 \\
\cline { 2 - 3 } & Significant & 0.000 \\
\hline
\end{tabular}

According to the above results, the KMO test value is 0.52, and the Bartlett spherical test value is 102.239, which is large, and its corresponding significance level $\mathrm{P}=0.000$, so the data is in accordance with the conditions for performing factor analysis.

Next, the extraction of the common factor is performed. Since the extraction factor must satisfy the eigenvalue greater than 1 , and from the analysis results of Table 2, there are five common factors with eigenvalues greater than 1 , and the remaining six factor eigenvalues are all below 1 , which does not meet the requirements. The model extracts 5 common factors from 11 initial variables. At the same time, according to Table 1, the extracted five principal component common factors represent the information amount of $84.325 \%$ of the original 11 indicators, which is greater than the $80 \%$ level required by the general, so it can be considered as a substitute for the original index.

Next, the five extracted common factors can be named by the method of factor rotation. In general, there are two ways to perform factor rotation, one is orthogonal rotation and the other is oblique rotation. This paper uses the maximum variance method of orthogonal rotation in SPSS.

From the results, the common factor can be named. The first extracted common factor F1 generally reflects the business capability of the enterprise; the second extracted common factor F2 generally reflects the solvency of the enterprise; the third extracted common factor F3 generally reflects the growth ability of the enterprise; the fourth extracted common factor F4 generally reflects the profitability of the enterprise; the fifth extracted common factor F5 generally reflects the asset management capability of the enterprise.

Next, the obtained common factor is used as a dependent variable for regression analysis, sample 
classification and evaluation, and the values of each common factor corresponding to each sample variable are obtained, and these values are called factor scores ${ }^{[4]}$. The factor score is the final embodiment of the factor analysis, and the factor score can be used to directly study the actual problem.

Table 1 Total variance interpretation

\begin{tabular}{|c|c|c|c|c|c|c|c|c|c|}
\hline \multirow{2}{*}{ No. } & \multicolumn{3}{|c|}{ Initial eigenvalue\% } & \multicolumn{3}{c|}{$\begin{array}{c}\text { Extract the sum of squared } \\
\text { loads \% }\end{array}$} & \multicolumn{3}{c|}{$\begin{array}{c}\text { Sum of squared rotational } \\
\text { loads \% }\end{array}$} \\
\cline { 2 - 12 } & Total & variance & Acum. & Total & Variance & Acum. & Total & Variance & Acum. \\
\hline 1 & 3.533 & 32.116 & 32.116 & 3.533 & 32.116 & 32.116 & 2.553 & 23.205 & 23.205 \\
\hline 2 & 2.253 & 20.481 & 52.598 & 2.253 & 20.481 & 52.598 & 2.040 & 18.549 & 41.754 \\
\hline 3 & 1.319 & 11.993 & 64.591 & 1.319 & 11.993 & 64.591 & 1.826 & 16.600 & 58.354 \\
\hline 4 & 1.125 & 10.228 & 74.819 & 1.125 & 10.228 & 74.819 & 1.682 & 15.292 & 73.646 \\
\hline 5 & 1.046 & 9.507 & 84.325 & 1.046 & 9.507 & 84.325 & 1.175 & 10.679 & 84.325 \\
\hline 6 & .682 & 6.199 & 90.525 & & & & & & \\
\hline 7 & .482 & 4.381 & 94.906 & & & & & & \\
\hline 8 & .285 & 2.589 & 97.495 & & & & & & \\
\hline 9 & .110 & .996 & 98.491 & & & & & & \\
\hline 10 & .090 & .818 & 99.309 & & & & & & \\
\hline 11 & .076 & .691 & 100.000 & & & & & & \\
\hline
\end{tabular}

Table 2 Component score coefficient matrix

\begin{tabular}{|c|c|c|c|c|c|}
\hline & \multicolumn{5}{|c|}{ Ingredient } \\
\cline { 2 - 5 } & 1 & 2 & 3 & 4 & 5 \\
\hline Roe $\left(x_{1}\right)$ & .152 & -.015 & .269 & .061 & .004 \\
\hline Total net profit margin $\left(x_{2}\right)$ & .119 & .168 & .212 & .082 & .024 \\
\hline Inventory turnover $\left(x_{3}\right)$ & .394 & -.149 & -.185 & .106 & -.044 \\
\hline Fixed asset turnover $\left(x_{4}\right)$ & -.223 & .336 & -.220 & .394 & -.276 \\
\hline Total asset turnover $\left(x_{5}\right)$ & .440 & -.055 & -.094 & -.201 & -.098 \\
\hline Accounts receivable turnover $\left(x_{6}\right)$ & -.064 & .031 & -.133 & .018 & .834 \\
\hline Main business income growth rate $\left(x_{7}\right)$ & .020 & .010 & -.213 & .500 & .038 \\
\hline Total asset growth rate $\left(x_{8}\right)$ & -.159 & -.113 & .151 & .478 & -.088 \\
\hline Net asset growth rate $\left(x_{9}\right)$ & -.156 & .062 & .591 & -.121 & -.153 \\
\hline Current ratio A $\left(x_{10}\right)$ & -.056 & .480 & .066 & -.148 & -.033 \\
\hline Quick ratio A $\left(x_{11}\right)$ & .038 & .355 & .112 & -.050 & .284 \\
\hline
\end{tabular}

From the above table 2 component score coefficient matrix, we can get the specific scores of the 11 indicators used in this paper one by one corresponding to 5 common factors. Using $\beta$ to represent the component score coefficient, the factor score function formula expressed as:

$$
\begin{aligned}
F_{1}= & 0.152 x_{1}+0.119 x_{2}+0.394 x_{3}-0.223 x_{4}+0.440 x_{5} \\
& -0.064 x_{6}+0.020 x_{7}-0.159 x_{8}-0.156 x_{9}-0.056 x_{10}+0.038 x_{11} \\
F_{2}= & -0.015 x_{1}+0.168 x_{2}-0.149 x_{3}+0.336 x_{4}-0.055 x_{5}+0.031 x_{6} \\
& +0.010 x_{7}-0.113 x_{8}+0.062 x_{9}+0.480 x_{10}+0.355 x_{11}
\end{aligned}
$$




$$
\begin{aligned}
& \qquad \begin{aligned}
F_{3}= & 0.269 x_{1}+0.212 x_{2}-0.185 x_{3}-0.220 x_{4}-0.094 x_{5}-0.133 x_{6} \\
& -0.213 x_{7}+0.151 x_{8}+0.591 x_{9}+0.066 x_{10}+0.112 x_{11}
\end{aligned} \\
& \qquad \begin{aligned}
F_{5}= & 0.004 x_{1}+0.024 x_{2}-0.044 x_{3}-0.276 x_{4}-0.098 x_{5} \\
& +0.834 x_{6}+0.038 x_{7}-0.088 x_{8}-0.153 x_{9}-0.033 x_{10}+0.284 x_{11}
\end{aligned} \\
& \text { Overall ratings }=\frac{23.205 F_{1}+18.549 F_{2}+16.600 F_{3}+15.292 F_{4}+10.679 F_{5}}{84.325}
\end{aligned}
$$

Finally, the overall scores of 20 companies are ranked, and the results are shown in the table below.

Table 3 Score Ranking Table

\begin{tabular}{ccccccccccccc}
\hline & \multicolumn{3}{c}{$\mathrm{F} 1$} & \multicolumn{3}{c}{$\mathrm{F} 2$} & \multicolumn{3}{c}{$\mathrm{F} 3$} & \multicolumn{3}{c}{$\mathrm{F} 4$} \\
Enterprise & Score & Rank & Score & Rank & Score & Rank & Score & Rank & Score & Rank & Score & Rank \\
\hline Jin Di & 1.28 & 1 & 1.74 & 2 & -0.11 & 12 & -0.11 & 10 & 0.98 & 3 & 0.82 & 1 \\
Xin Hu & -0.36 & 13 & 1.39 & 4 & 1.14 & 3 & 0.03 & 9 & 0.61 & 4 & 0.51 & 2 \\
Lu jia zui & 0.81 & 6 & -1.00 & 19 & 0.13 & 11 & 2.14 & 1 & -0.09 & 7 & 0.41 & 3 \\
Xin cheng & 0.88 & 5 & -0.95 & 17 & 0.18 & 10 & 0.60 & 4 & 1.38 & 2 & 0.35 & 4 \\
Bin jiang & 1.04 & 3 & 0.24 & 7 & 0.42 & 6 & -0.18 & 11 & -0.35 & 11 & 0.34 & 5 \\
Hua xia & -0.07 & 12 & -0.66 & 15 & 1.62 & 2 & 0.50 & 5 & -0.60 & 19 & 0.17 & 6 \\
Bao li & 0.65 & 8 & 0.24 & 6 & 0.21 & 9 & -0.53 & 15 & -0.40 & 14 & 0.13 & 7 \\
Hua qiao & 0.38 & 10 & -0.37 & 13 & 0.59 & 4 & -0.30 & 12 & -0.05 & 6 & 0.08 & 8 \\
Wo long & 0.33 & 11 & 1.87 & 1 & -0.87 & 15 & -1.22 & 19 & -0.33 & 10 & 0.07 & 9 \\
Wan ke A & 0.67 & 7 & -0.80 & 16 & 0.30 & 8 & 0.26 & 7 & -0.43 & 15 & 0.06 & 10 \\
Hua fa & -1.24 & 17 & -0.08 & 10 & -0.33 & 13 & 0.22 & 8 & 3.43 & 1 & 0.05 & 11 \\
Ge li & -1.54 & 18 & 0.39 & 5 & 2.40 & 1 & -0.66 & 16 & -0.59 & 18 & -0.06 & 12 \\
Guang M. & 1.13 & 2 & -0.24 & 12 & -0.88 & 16 & -0.44 & 14 & -0.55 & 17 & -0.06 & 13 \\
Lv di & 0.99 & 4 & -0.97 & 18 & -0.54 & 14 & -0.35 & 13 & -0.44 & 16 & -0.17 & 14 \\
Rong an & -1.61 & 19 & 1.57 & 3 & -1.35 & 20 & 2.00 & 2 & -1.31 & 20 & -0.17 & 15 \\
Tai he & -0.65 & 15 & -0.61 & 14 & 0.48 & 5 & 0.41 & 6 & -0.40 & 13 & -0.20 & 16 \\
Jing tou & -0.56 & 14 & 0.17 & 8 & 0.31 & 7 & -0.89 & 17 & -0.38 & 12 & -0.27 & 17 \\
Hua li & -0.71 & 16 & -0.22 & 11 & -1.25 & 18 & 1.35 & 3 & -0.25 & 9 & -0.28 & 18 \\
Sha he & 0.42 & 9 & 0.06 & 9 & -1.13 & 17 & -1.05 & 18 & 0.02 & 5 & -0.28 & 19 \\
Hai hang & -1.84 & 20 & -1.80 & 20 & -1.31 & 19 & -1.78 & 20 & -0.24 & 8 & -1.51 & 20 \\
\hline
\end{tabular}

As can be seen from the above table, Jin di Group ranks first in the first common factor. This factor reflects the business capability of the company. Among the 20 real estate companies participating in the research, 11 companies scored positive, and another 9 The score is negative, it can be seen that the overall operating capacity of the real estate enterprise is balanced; the second common factor of Wolong Real Estate ranks first, this factor reflects the solvency of the enterprise, 11 companies have negative scores, and the other 9 are positive Value, it can be seen that some real estate companies have poor solvency; the third common factor reflects the growth ability, 11 companies score positive, and the other 9 are negative, showing that the overall growth capacity of real estate enterprises is fairly balanced; The four common factors reflect the profitability, 11 companies have negative scores, and 9 are positive. The difference between the highest value and the lowest value is large. It can be seen that the profitability of real estate enterprises varies greatly. The fifth common factor reflects the assets. Management ability, 9 companies scored negative, 11 scores were positive, showing that the overall asset management ability is balanced. 


\section{Conclusion}

According to the comprehensive score ranking, there are 9 companies with a negative composite score and 11 companies with a positive score. In general, the financial performance of listed companies in the real estate industry is balanced. The top three are Jindi, Xinhu Zhongbao and Lujiazui. Jin di ranks first in terms of operating capacity, second in solvency, and third in asset management, but ranks in growth and profitability. Therefore, the company should strengthen the company's net profit growth rate and promote the company's long-term profitability and development. Lujiazui's comprehensive ability ranked third, profitability ranked first, while the other four common factors ranked relatively low. Therefore, it can be explained that the profitability indicator plays a decisive role in the evaluation of financial performance. Among them, Lujiazui Group has a weak performance in solvency, and the company needs to carry out strict asset management and control in the future to enhance its solvency. In summary, different companies have obvious differences in terms of profitability, management ability, solvency, and development capability. Top management should make decisions based on the characteristics of the company, and find out the company based on the actual background. Competitive advantage to enhance the company's competitiveness.

\section{References}

[1] Shangguan Fei, Shu Changjiang. Factor Analysis and Evaluation of Regional Competitiveness in Provinces in the Central Region [J]. Statistics and Decision, 2011, 9): 71-3.

[2] HARVIE C, VALADKHANI A, CHANCHARAT S. A factor analysis of international portfolio diversification [J]. Studies in Economics \& Finance, 2008, 25(3): 165-74.

[3] Shao Tiezhu, Yu Sha. Financial performance evaluation of the real estate listed companies based on factor analysis method [J]. Science-Technology and Management, 2013, 15(1): 90-3.

[4] Lu Wendai, Zhu Hongbing. SPSS Statistics Analysis. The Fifth Version. [M]. Publishing House of Electronics Industry, 2015. 